\title{
PRODUÇÃO TEXTUAL E OUTROS EIXOS NO ENSINO MÉDIO: COM QUE FREQUENCIA ELES SÃO TRABALHADOS?
}

\author{
Laécio Eugênio da Silva ${ }^{1}$; Angela Valéria Alves de Lima²
}

\section{INTRODUÇÃO}

O presente estudo foi desenvolvido no grupo de estudos NUPEDE (Núcleo de pesquisa em discurso e ensino) da Universidade Federal Rural de Pernambuco - Unidade Acadêmica de Garanhuns (UFRPE - UAG) e o intuito era observar a produção textual nas aulas de Língua Portuguesa do Ensino Médio, a fim de se constatar com que frequência ela ocorria em sala. Considerando a escrita como um processo, apontada por Dolz, Gagnon e Decândio (2010), foi feito um comparativo entre esse eixo e a Literatura - Escolas Literárias ${ }^{3}$, a Leitura e a Gramática. Evidenciando que apenas dois eixos foram trabalhados nas três turmas observadas, um dos eixos foi trabalhado em duas, das três e um deles foi totalmente esquecido.

\section{FUNDAMENTAÇÃO TEÓRICA}

Desde os primeiros anos, a escola aponta a escrita como um dos eixos que devem ser ensinados, porém, o que ocorre com frequência, é justamente essa escrita não ter um objetivo, um "para que escrever?". Bunzen (2006) aponta que, muitas vezes, são solicitadas aos alunos produções de texto, sem definir um objetivo específico, sem uma preocupação sociointerativa aparente, o que acarreta na desmotivação do aluno, fazendo-o deixar essa habilidade de lado durante sua vida escolar. O autor ainda afirma que no Ensino Médio, a escrita, que neste caso, está diretamente relacionada à redação, é sempre colocada em segundo plano. E muitas vezes, não é caracterizada como um processo, como é caracterizada por Dolz, Gagnon e Decândio (2010) ao apontarem a contextualização, os conteúdos temáticos, a planificação, a textualização e a releitura, rescrita e revisão como sendo as cinco operações que contribuem de forma significativa para o desenvolvimento de um aluno-escritor.

\section{METODOLOGIA}

O estudo em questão consiste em uma pesquisa de campo com caráter quantitativo e

\footnotetext{
${ }^{1}$ Curso: Licenciatura em Letras - Português, Inglês e suas literaturas. Instituição: Universidade Federal Rural de Pernambuco - Unidade Acadêmica de Garanhuns (UFRPE - UAG). E-mail: laecio.eugenio@ hotmail.com.

2 Titulação: Doutora em Linguística, Instituição: Universidade Federal Rural de Pernambuco - Unidade Acadêmica de Garanhuns (UFRPE - UAG), e-mail: angelaprofessora@uol.com.br
} 
qualitativo. As observações aconteceram no período de três semanas em três turmas: uma do primeiro, uma do segundo e uma do terceiro ano, em uma Escola de Referência em Ensino Médio da cidade de Garanhuns - PE, totalizando 54 horas/aulas observadas. O método utilizado foi o da Observação do tipo participante, ou seja, com a participação direta do observador na coleta dos dados. Posteriormente, ocorreu a análise dos dados, comparando com que frequência a escrita aconteceu em sala em relação aos demais eixos.

\section{RESULTADOS E DISCUSSÕES}

Nas três turmas observadas, pode-se constatar que a produção textual ocorreu de maneira semelhante. $\mathrm{O}$ docente chegava na sala, dizia que naquele dia iriam trabalhar a redação, e pedia para os alunos escreverem. Não havia uma preparação anterior, o máximo que um dos professores fez foi mostrar como o texto dissertativo-argumentativo se estrutura, em introdução, desenvolvimento e conclusão (isso aconteceu na turma do terceiro ano). Isso é importante, já que, cada gênero textual se compõe de uma forma, mas a escrita não se resume a isso. Ela acontece por meio de um processo contínuo e árduo, exigindo dedicação do docente e do discente.

Os gráficos abaixo mostram a posição que a produção textual é colocada na sala de aula ao lado dos demais eixos, em cada ano do ensino médio. Vejamos:

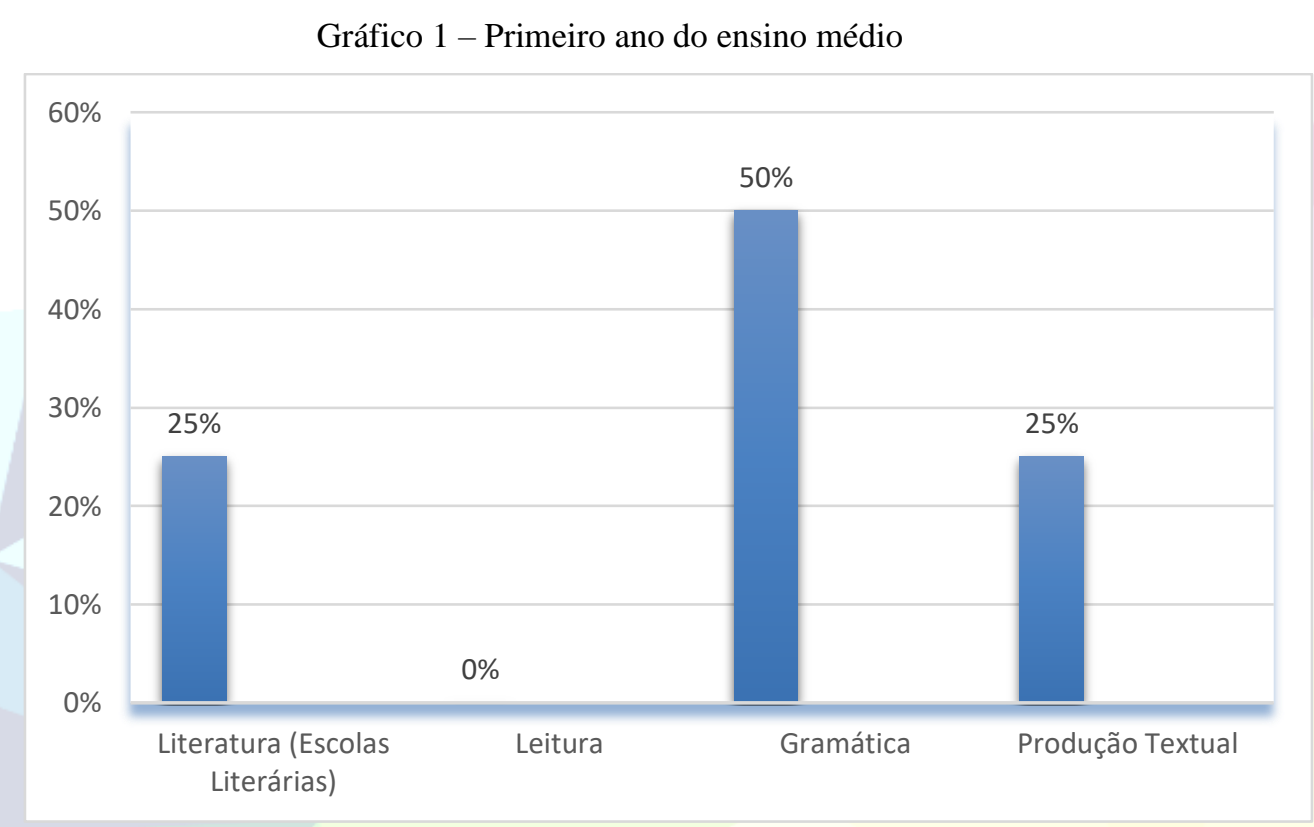

No gráfico 1, podemos observar que a produção textual empata diretamente com o ensino de literatura voltado para as escolas literárias. Os dois eixos foram trabalhados em média, em quatro horas/aulas e meia durante o período de observação. A gramática foi abordada em 
nove aulas, das dezoito observadas. Já a leitura foi totalmente deixada de lado.

Esses dados podem ser preocupantes. Sabemos que a gramática é e deve ser ensinada, o problema aparece quando isso se torna o foco das aulas, quando essa gramática é ensinada de forma solta e sem nenhum propósito evidente para o aluno. $\mathrm{O}$ fato de a leitura ter sido deixada totalmente de lado também é preocupante, pois como já foi dito e é sabido por nós, a leitura está diretamente relacionada ao processo de escrita.

O gráfico só confirma o que Bunzen (2006) diz em relação às aulas de português. O autor afirma que elas são subdivididas em: gramática, literatura e redação; sendo os dois primeiros eixos, geralmente, os mais enfatizados. A redação, que no Ensino Médio está sempre ligada ao trabalho com escrita na sala de aula, conforme ele, é sempre colocada em segundo plano.

Gráfico 2 - segundo ano do ensino médio

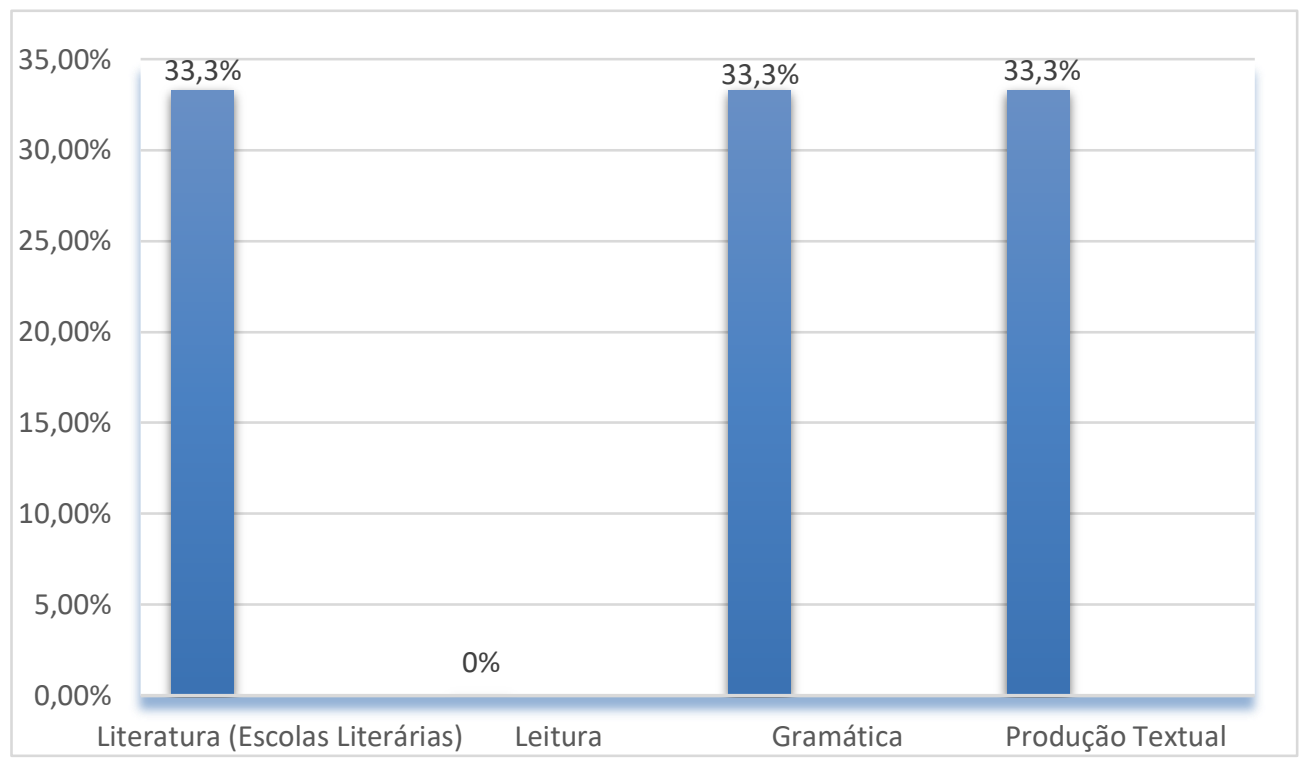

O gráfico 2 nos mostra que, mais uma vez, a literatura e a produção textual foram trabalhados com mesma distribuição de tempo. Só que dessa vez, a gramática se encontra no mesmo patamar desses dois eixos, ou seja, houve uma melhor divisão do tempo por parte do professor, nas aulas observadas. No entanto, a leitura continua sendo esquecida pelo docente.

$\mathrm{O}$ fato de nessa turma o professor ter distribuído melhor o tempo para se trabalhar diferentes eixos, deve ser visto como positivo. Isso nos mostra que, apesar de haver aqueles que acabam tendo a gramática como foco (como nos mostra o gráfico 1), há também aqueles que tentam explorar outros eixos do ensino da língua (como nos mostra o gráfico 2), ao colocar o letramento literário e a produção textual ao lado do ensino de gramática. A leitura continuar sendo ignorada pelo docente em sala de aula, deve ser duas vezes mais preocupante, já que no 
primeiro ano o professor fez o mesmo. Aqui já podemos supor que os problemas, as dificuldades encontradas pelos alunos na hora de escrever podem estar diretamente ligadas a esse eixo, melhor dizendo, a falta dele.

Gráfico 3 - terceiro ano do ensino médio

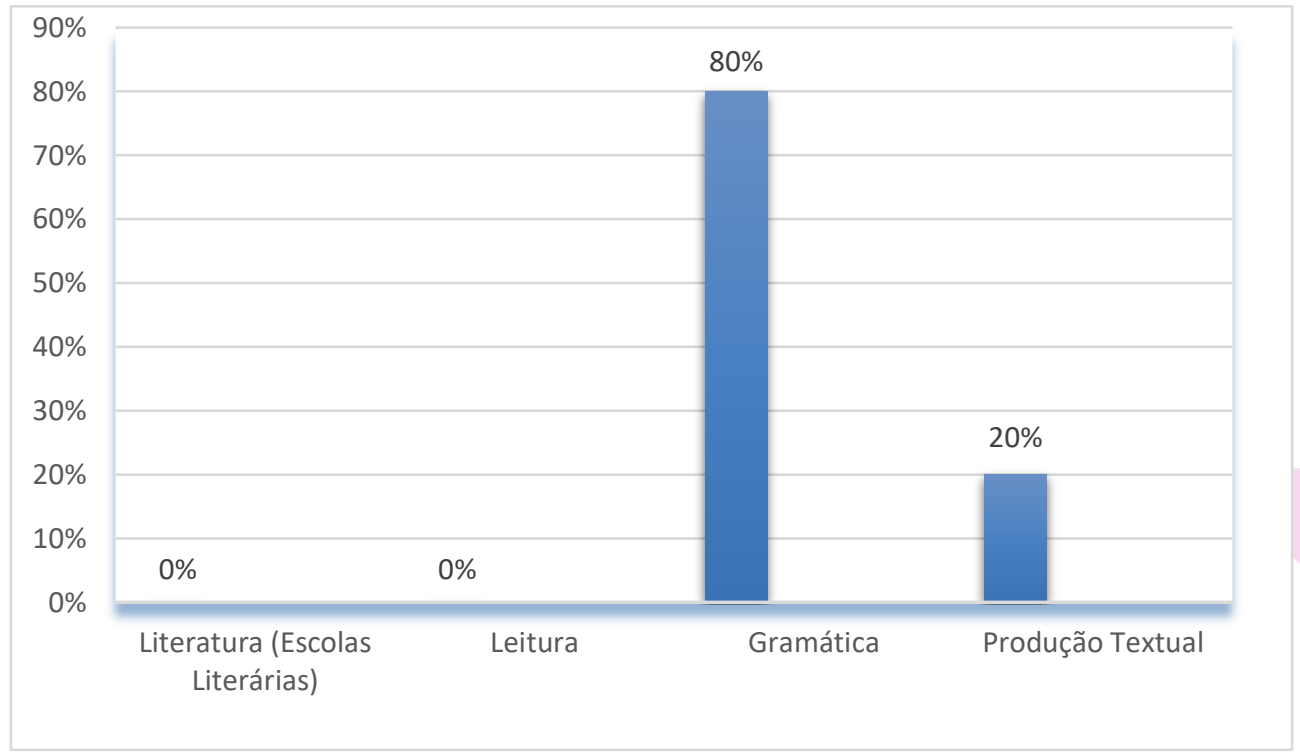

No gráfico 3, podemos perceber que houve uma priorização do eixo gramática, e mais uma vez a produção textual foi deixada em segundo plano (como mostrou o gráfico 1), mas ainda assim, não deixou de ser trabalhada. Ao contrário dos eixos literatura e leitura, que foram totalmente esquecidos.

O Ensino Médio em si, na maioria das vezes, é voltado a preparar o aluno para o vestibular, o terceiro ano mais que os anos anteriores. Algo importante e que deve ser dito, é que, nesse caso, a predominância em se trabalhar gramática na sala de aula, está diretamente relacionada com a produção textual. O docente, ao ensinar os conteúdos voltados a gramática, sempre enfatizava a importância deles para se conseguir escrever um bom texto, ao contrário dos professores das outras turmas observadas. Isso deve ser visto como algo bom, já que esse conhecimento é necessário para se um texto bem escrito, no entanto, não é o único elemento essencial. O educador não dedicar um tempo para trabalhar o eixo leitura, se torna mais uma vez o problema. Dessa vez, o eixo literatura também foi totalmente esquecido.

\section{CONCLUSÕES}

Considerando a importância de se trabalhar a produção escrita na sala de aula, de uma maneira que seja produtiva tanto para o professor como também para o aluno, esta pesquisa se propôs a evidenciar se a produção textual era de fato trabalhada no ensino médio. Comparando 
a frequência que esse eixo era enfatizado em relação aos demais.

Por fim, ratificamos que se trabalhar produção textual não é nada fácil, por se tratar de um processo que exige tempo e dedicação contínua das duas partes (docente e discente), mas não é algo impossível. Talvez, futuramente esse eixo seja melhor trabalhado nas escolas.

\section{REFERÊNCIAS}

BUNZEN, Clecio. Da era da composição à era dos gêneros: o ensino de produção de texto no ensino médio. In: BUNZEN, C.; MENDONÇA, M. (Orgs.). Português no ensino médio e formação do professor. São Paulo, Parábola, 2006. p. 139-161.

DOLZ, Joaquim; DECÂNDIO, Fabrício; GAGNON, Roxane. Produção escrita e dificuldades de aprendizagem. Campinas: Mercado de Letras, 2010. 